\title{
Organophosphate Poisoning Due to a Wheat Bagel
}

\author{
Cemil Kavalci ${ }^{1}$, Polat Durukan ${ }^{2}$, Mehmet Ozer $^{1}$, Yunsur Cevik ${ }^{1}$ and Gülsüm Kavalci ${ }^{3}$
}

\begin{abstract}
Objective Organophosphate compounds are possibly the most widely-used insecticides worldwide. Organophosphate compounds cause poisoning, inhibiting acetylcholinesterase at the cholinergic synapses. Civilian casualties resulted from a terrorist attack with sarin in a Tokyo subway. Recent terrorist activities have also raised concerns that organophosphate or nerve agents may be used as a weapon of terror or mass destruction. Methods In this study, an extraordinary type of mass poisoning was evaluated. Especially by focusing on the way of poisoning, the demographic features and clinical findings of patients were analyzed.

Results After eating a wheat bagel, 13 patients with organophosphate poisoning were admitted to our emergency department. Seven were males and 6 were females. The mean age of the patients was $26 \pm 13.9$. The mean serum acetylcholinesterase level was $2945.1 \pm 2648.9 \mathrm{U} / \mathrm{L}$. Nine patients who had supportive treatment and who were given atropine and pralidoxime were hospitalized approximately $6.8 \pm 6.5$ days. All of the patients recovered after the treatment and no deaths occurred.

Conclusion If organophosphate poisoning is not diagnosed and treated in time, it may be fatal. When cases of food poisoning are admitted to the hospital, attention must be taken especially if it is a mass poisoning.
\end{abstract}

Key words: organophosphates, poisoning, emergency department

(Inter Med 48: 85-88, 2009)

(DOI: 10.2169/internalmedicine.48.1559)

\section{Introduction}

Organophosphate (OP) compounds are possibly the most widely-used insecticides worldwide. The use of OP compounds is responsible for about 200,000 poisoning victims per year world-wide (1).

Organophosphate compounds cause poisoning, inhibiting acetylcholinesterase (AChE) at the cholinergic synapses (24). As a result of this enzyme inhibition, the substrate acetylcholine (ACh) accumulates. The continued stimulation and eventual paralysis of the ACh receptors account for the clinical signs and symptoms of OP poisoning, including muscarinic, nicotinic, and central nervous system effects $(2$, 5).

Organophosphate exposures occur in farm and factory workers, military personnel, and exterminators. They were also used during World War II (6). Civilian casualties resulted from a terrorist attack with sarin in a Tokyo subway. Recent terrorist activities have also raised concerns that or- ganophosphate or nerve agents may be used as a weapon of terror or mass destruction (2, 7-9). Especially in mass poisonings, forensic issues are a concern. Also there have been some publications on intentional organophosphate poisoning in animals (10-12), but very less in humans (13). It was reported that food contamination by organophosphates in humans mostly occurs in farmers and agriculture workers (14, 15).

In this study, an extraordinary type of mass poisoning was evaluated. Especially by focusing on the way of poisoning, the demographic features and clinical findings of patients were analyzed.

\section{Materials and Methods}

The study was performed retrospectively by evaluating the files of thirteen patients who were admitted to the emergency department of Atatürk Training and Research Hospital due to OP intoxication. Anamneses were obtained from the relatives of patients. It was clarified that the poisoning oc-

${ }^{1}$ Atatürk Training and Research Hospital Emergency Department, Ankara, Turkey, ${ }^{2}$ Department of Emergency Medicine, Erciyes University Faculty of Medicine, Kayseri, Turkey and ${ }^{3}$ Department of Anesthesia and Reanimation, Trakya University Faculty of Medicine, Edirne, Turkey Received for publication August 4, 2008; Accepted for publication September 23, 2008 Correspondence to Dr. Cemil Kavalci, cemkavalci@yahoo.com 
Table 1. The Clinical and Demographic Features of the Patients

\begin{tabular}{|c|c|c|c|c|}
\hline $\begin{array}{l}\text { Number } \\
\text { of patient }\end{array}$ & Age & Gender & $\begin{array}{l}\text { Serum Acetyl } \\
\text { cholinesterase level (U/L) }\end{array}$ & Symtomps \\
\hline 1 & 20 & $\mathrm{~F}$ & 470 & Fasciculation \\
\hline 2 & 17 & M & 5466 & Loss of consciousness \\
\hline 3 & 16 & $\mathrm{~F}$ & 1290 & Nausea, Vomiting, Dizziness \\
\hline 4 & 25 & $\mathrm{M}$ & 2534 & Fasciculation, Dizziness \\
\hline 5 & 47 & $\mathrm{~F}$ & 470 & Fasciculation, Dizziness \\
\hline 6 & 16 & $\mathrm{~F}$ & 1055 & Nausea, Vomiting, Dizziness \\
\hline 7 & 18 & M & 868 & Nausea, Vomiting, Dizziness \\
\hline 8 & 18 & M & 1080 & Nausea, Dizziness, Fatigue \\
\hline 9 & 19 & M & 563 & Vomiting, Fatigue, Hedache \\
\hline 10 & 21 & $\mathrm{~F}$ & 5840 & Nausea, Vomiting \\
\hline 11 & 23 & $\mathrm{~F}$ & 7830 & Nausea, Vomiting, Dizziness \\
\hline 12 & 59 & M & 6200 & Nausea, Vomiting \\
\hline 13 & 41 & M & 4621 & Nausea, Vomiting \\
\hline
\end{tabular}

curred with the ingestion of a kind of wheat bagel called "simit" in Turkish. The criminal investigation revealed that the contamination of 2,2-dichlorovinyl dimethyl phosphate (DDVP) into the wheat bagel was not accidental, but intentional; a competitor firm's worker added DDVP to the wheat bagel dough.

The diagnosis of acute OP poisoning was based on the following criteria: 1) history of exposure to or contact with insecticide; 2) characteristic clinical signs and symptoms of OP poisoning; 3) improvement of signs and symptoms with atropine and oximes, and 4) decreased level of cholinesterase (AChE) enzyme in the serum.

Data regarding the age, sex, time of the admission, physical examination signs, levels of AChE, consultations, hospitalizations and the date of discharge were obtained from the patient file. These were recorded using standardized data collection forms and were analyzed with a SPSS software program.

\section{Results}

After eating a wheat bagel, 13 patients with OP poisoning were admitted to our emergency department. The first patient admitted to our department had contraction of neck muscles, nausea and vomiting. Then we suspected OP poisoning. Seven were males and 6 were females. Of the patients, 7 came to the hospital by themselves; the other 6 patients were brought by ambulance service. The mean age of the patients was $26 \pm 13.9$. The clinical and demographic features of the patients are listed in Table 1. Nine of these patients' personally applied to our service and 4 of them did so formally. Average admission time was $348.4 \pm 200.3$ minutes (min: 90, max: 720 minutes).

General conditions of patients were as follows; $53.8 \%$ of them were good; $38.5 \%$ of them were moderately ill and $7.7 \%$ of them were in serious condition. Their mean systolic blood pressure was $117.6 \pm 26.8 \mathrm{mmHg}$, the mean diastolic blood pressure was $67.6 \pm 12.8 \mathrm{mmHg}$; and the mean pulse rate was $82 \pm 9$ /minutes. In $61.5 \%$ the physical examination was normal whereas $23.1 \%$ of them had fasciculation in neck muscles; $7.7 \%$ of them had miosis and $7.7 \%$ of them had loss of consciousness. Moreover, serum AChE level in 4 patients was normal but it was low in 9 patients. The median serum AChE level was 1,290 U/L (IQR 4938) (Normal: 3,714-11,513 U/L)). While 4 patients, who had supportive treatment in emergency department, were observed and discharged in the same day, 9 patients who had supportive treatment and were given atropine and pralidoxime (PAM) were hospitalized for approximately $6.8 \pm 6.5$ days. All of the patients recovered after the treatment and no deaths occurred.

\section{Discussion}

Acute ingestion with organophosphorus pesticides causes severe toxicity; it causes thousands of deaths each year across the developing world (16). Whitlow et al reported that tetrametthyllenedisulfotetramine is a lethal, neurotoxic rodenticide that has been the source of numerous intentional poisonings in China (13). They found that 61 children ate cake in the school cafeteria and were poisoned with this rodenticide. It was said that a man had added this toxin to 
cake dough and caused the death of 38 people. Similarly the present patients who ate a wheat bagel were poisoned by DDVP, and by chance we had no mortality.

Yurumez et al (17) reported the mean time to hospital admission was $3.9 \pm 3.1$ hours; that of the present patients was longer. The reason may be the fact that our patients were first taken to the district hospital, than to our hospital.

The diagnosis of acute OP poisoning is based on a history of exposure to the insecticide, characteristic clinical signs and symptoms of OP poisoning, clinical improvement after treatment with atropine and oximes, and decreased serum AChE activity $(18,19)$.

As reported in the literature $(2,5,20,21)$, the present patients also had nicotinic, muscarinic symptoms concerning the central nervous system like nausea, vomiting, dizziness, fatigue, fasciculation and coma. It has been reported that the most common symptom is miosis. It was seen in $7.7 \%$ of our patients.

Treatment of OP poisoning consists of general supportive measures, decontamination, prevention of absorption and intensive respiratory support. Specific therapy includes the administration of antidotes and is based on the degree of toxicity (2). Atropine antagonizes muscarinic symptoms but it has no effect on nicotinic receptors. In moderate to severe exposure, atropine is intravenously administered in a dose of 2 to $4 \mathrm{mg}$ for adults and $0.05 \mathrm{mg} / \mathrm{kg}$ for children. This dose is doubled every 5 to 10 minutes until muscarinic symptoms are relieved (2). The first 24 - 48 hours after the exposure is a critical period and in this period it may be necessary to give antidote. In accordance with the literature we gave atropine to $84.6 \%$ of our patients until muscarinic symptoms were decreased. PAM activates cholinesterase enzyme. PAM should be given before the irreversible attachment. The recommended dose is $1 \mathrm{~g}$ for adults and $20-40 \mathrm{mg} / \mathrm{kg}$ for children. It should be infused in normal saline over $30 \mathrm{~min}$. This infusion may be repeated in 1 hour, and multiple doses may be necessary (2). We gave PAM to $69.2 \%$ of the patients at a dose of $1 \mathrm{~g} / \mathrm{h}$. Then, the symptoms disappeared and AChE levels were normalized. The use of hemoperfusion is questionable. While textbooks state that hemoperfusion is ineffective, some researchers claim that it is effective for OP poisoning $(2,22)$. We did not perform hemoperfusion for the present patients.

The mean admission rate was reported as $2.9 \pm 2.1$ days by Seydaoglu et al (21), 5.05 days by Dippenaar et al (22); our mean admission time was $6.8 \pm 6.5$ days which is a little bit longer.

It is described in literature that OP poisoning is an important cause of mortality and morbidity $(6,23,24)$. Yurumez et al (17) and Seydaoglu (21) et al reported $9 \%$ and $8.3 \%$ mortality rates, respectively. In the present study, no deaths occurred; we consider this to be the result of early diagnosis and proper treatment.

It is said that necrotizing pancreatitis (25), coital-like involuntary movements (26) and intermediary syndrome may develop in patients after OP poisoning $(27,28)$. In our series these complications were not seen.

\section{Conclusion}

If OP poisoning is not diagnosed and treated in time, it may be fatal. When cases of food poisoning are admitted to the hospital, special attention must be taken especially if it is a mass poisoning.

\section{References}

1. Eddleston M, Buckley NA, Eyer P, Dawson AH. Management of acute organophosphorus pestiside poisoning. Lancet 371: 597-607, 2008.

2. Robey WC, Megs JM. Insecticide, herbicides, rodenticides. In: Emergency Medicine. A Comprehensive Study Guide. 5th ed. Tintinalli JE, Kelen GD, Stapczynski JS, Eds. McGraw-Hill, NY, 2000: 1174-1182.

3. Batra AK, Keoliya AN, Jadhav GU. Poisoning: an unnatural cause of morbidity and mortality in rural India. Journal of the Association of Physicians of India 51: 955-999, 2003.

4. Clark RF. Insecticides: Organic Phosphorus Compounds and Carbamates. In: Goldfrank's Toxicologic Emergencies. 8th ed. Flomenbaum NE, Goldfrank LR, Hoffman RS, et al, Eds. McGraw-Hill, NY, 2006: 1497-1512.

5. Chuang FR, Jang SW, Lin JL, Chern MS, Chen JB, Hsu KT. QTc prolongation indicates a poor prognosis in patients with organophosphate poisoning. Am J Emerg Med 14: 451-453, 1996.

6. Jeyaratnam J. Acute pesticide poisoning: a major global health problem. World Health Stat Q 43: 139-144, 1990.

7. Yanagisawa N, Morita H, Nakajima T. Sarin experiences in Japan: Acute toxicity and long-term effects. J Neurol Sci 249: 76-85, 2006.

8. Nouira S, Abroug F, Elatrous S, Boujdaria R, Bouchoucha S. Prognostic value of serum cholinesterase in organophosphate poisoning. Chest 106: 1811-1814, 1994.
9. Senanayake N, Karalliedde L. Neurotoxic effects of organophosphorus insecticides, an intermediate syndrome. $\mathrm{N}$ Engl J Med 316: 761-763, 1987.

10. Motas-Guzman M, Marla-Mojica P, Romero D, Martinez-Lopez E, Garcia- Fernandez AJ. Intentional poisoning of animal in southeastern Spain: a review of the veterinary toxicology service from Murcia, Spain. Vet Hum Toxicol 45: 47-50, 2003.

11. Calzetta L, Cavaliere M, Ruggeri E, Ricci A, Crescenzo G, Amorena M. Incidence of intentional poisoning of dogs in the Abruzzo region of Italy. Vet Hum Toxicol 44: 111-113, 2002.

12. Guitart R, Manosa S, Guerrero X, Mateo R. Animal poisonings: the 10-year experience of a veterinary analytical toxicology laboratory. Vet Hum Toxicol 41: 331-335, 1999.

13. Whitlow KS, Belson M, Barrueto F, Nelson L, Henderson AK. Tetramethylene- disulfotetramine: Old agent and new terror. Ann Emerg Med 45: 609-613, 2005.

14. Littcfield MH. Estimates of acute pesticide poisoning in agricultural workers in less developed countries. Toxicol Rev 24: 271278, 2005.

15. Chowdhury AN, Banerjee S, Brahma A, Weiss MG. Pesticide practices and suicide among farmers of the sundarban region in India. Food Nutr Bull 28: 381-391, 2007.

16. Buckley NA, Eddleston M, Szinicz L. Oximes for acute organophosphate pesticide poisoning. Cochrane Database Syst Rev 2005; 1: CD005085. Review. 
17. Yurumez Y, Durukan P, Yavuz Y, et al. Acute organophosphate poisoning in university hospital emergency room patients. Intern Med 46: 965-969, 2007.

18. Aygun D, Doganay Z, Altintop L, et al. Serum acetylcholinesterase and prognosis of organophosphate poisoning. J Toxicol Clin Toxicol 40: 903-910, 2002.

19. Tsao TC, Juang YC, Lan RS, Shieh WB, Lee CH. Respiratory failure of acute organophosphate and carbamate poisoning. Chest 98: 631-636, 1990

20. Altıntop L, Aygun D, Sahin H, et al. In acute organophosphate poisoning, the efficacy of hemoperfusion on clinical status and mortality. J Intensive Care Med 2005; 20: 346-350, 2005.

21. Seydaoglu G, Satar S, Alparslan N. Frequency and Mortality Risk Factors of Acute Adult Poisoning in Adana, Turkey, 1997-2002. Mt Sinai J Med 72: 393-401, 2005.

22. Dippenaar R, Diedericks RJ. Paediatric organophosphate poisoning - a rural hospital experience. S Afr Med J 95: 678-681, 2005.

23. Buckley NA, Karalliedde L, Dawson A, Senanayake N, Eddleston $\mathrm{M}$. Where is the evidence for treatments used in pesticide poison- ing? Is clinical toxicology fiddling while the developing world burns? J Toxicol Clin Toxicol 42: 113-116, 2004.

24. Rahimi R, Nikfar S, Abdollahi M. Increased morbidity and mortality in acute human organophosphate-poisoned patients treated by oximes: a meta-analysis of clinical trials. Hum Exp Toxicol 25 : 157-162, 2006.

25. Panieri E, Krige JE, Bornman PC, Linton DM. Severe necrotizing pancreatitis caused by organophosphate poisoning. J Clin Gastroenterol 25: 463-465, 1997.

26. Tsai MH, Tsai NW, Chen SF, et al. Organophosphate intoxicationrelated coital-like involuntary movements: report of a case. Acta Neurol Taiwan 15: 34-37, 2006.

27. Wananukul W, Kiateboonsri S, Thithapandha A. The "intermediate syndrome" as critical sequelae of organophosphate poisoning: the first report of two cases in Thailand. J Med Assoc Thai 88: 13081313, 2005.

28. Aygun D. Diagnosis in an acute organophosphate poisoning: report of three interesting cases and review of the literature. Eur $\mathbf{J}$ Emerg Med 11: 55-58, 2004.

(C) 2009 The Japanese Society of Internal Medicine http://www.naika.or.jp/imindex.html 